\title{
Leadership-Powerlessness and Workplace Governance: A Managerial Behavior Context
}

\author{
Miebi Ugwuzor, Kuroakegha B. Basuo, and Marian L. Apoh
}

\section{ABSTRACT}

The growth, sustainability and success of a corporate entity is largely predicated on its framework of interconnecting operational mechanisms, relationships, and processes. As a norm, statutory functions and institutions are enacted in firms to ensure that corporate obligated responsibilities, to themselves as well as their stakeholders, are carried out in a manner that bequeaths enormous benefits. It is a commonsensical expectation that persons saddled with the responsibility to drive these processes, possess requisite and commensurate capacity to act in positive organizational result-oriented directions. However, Executive functionaries in corporate entities seem incapacitated to the extent that the desirable outcomes are not achieved. This work was to determine the contextual behavioral implications of powerlessness in persons occupying leadership positions with a view to highlighting the psychological promptings of the leaders as well as the intruding influences militating against them. This will give a broad knowledge of the issues at stake and a clearer understanding of the solutions proffered. The apparent unencouraging outcomes of corporate entities in Nigeria gave the impetus to this Paper to explore Leadership-powerlessness as a function of the empowerment capacity levels of executive functionaries vis-à-vis workplace governance. This paper regards workplace governance as an end indicative of outcomes that make for growth, sustainability, and survival of corporate entities. The study also suggested ways forward that will mitigate the leadership-powerlessness quagmire.

Keywords: corporate entity, endopowerlessness, exopowerlessness, Nigeria.
Submitted : November 02, 2021

Published : November 26, 2021

ISSN: 2507-1076

DOI: $10.24018 /$ ejbmr.2021.6.6.1159

\section{Miebi Ugwuzor*}

Department of Management, Niger Delta University, Nigeria.

(email:ebiugwuzor@yahoo.com)

Kuroakegha Bio Basuo

Department of Management, Niger Delta University, Nigeria.

(email: kuroakeghabasuo@yahoo.com)

Marian Lawrence Apoh

Department of Management, Niger Delta University, Nigeria.

(email: Marian_apoh@yahoo.co.uk)

*Corresponding Author

\section{INTRODUCTION}

Nigeria is still regarded as developing more than six decades after her Political independence. Development in itself is continuous and relative as even the countries that are termed developed are still developing in some key areas of endeavors. However, one generic term that has seem to crop to the fore in development literature is 'governance'. Governance is a key factor in the determination of the pace and magnitude of development. The World Bank made popular the governance concept in its report on Governance and Development (World Bank, 1992). Although a term in rational discourse from time immemorial, the said report regarded good governance as an essential complement to sound economic policies and is central to creating and sustaining an environment which fosters strong and equitable development. The World Bank opines that the components of good governance should include capacity and efficiency in public sector management, accountability, legal framework for development, and information and transparency .To measure the quality of governance through the Worldwide Governance Indicators, the concept was unbundled in six dimensions which include voice and accountability, political stability and lack of violence, government effectiveness, regulatory quality, rule of law as well as control of corruption. The International Monetary Fund (IMF, 2005) has also advocated the promotion of good governance for economic prosperity and suggests critical areas of concern to include the adherence to the rule of law, improvement in the efficiency and accountability of the public sector as well as the tackling of corruption. Noncompliance to these terms and conditions as advocated by the International Monetary Fund (IMF) could lead to denial of access to loan facilities from the United Nation's body. Governance has been seen from various perspectives such as international affairs, where the analysis of good governance looks at the relationships between governments and markets; governments and citizens; governments and the private or voluntary sector; elected officials and appointed officials as well as between government and civil society Organizations (Agere, 2000). Another perspective to this analysis is in national governments. In this situation, governance is analyzed in the context of countries in terms of the extent to which expectations of citizens are met in areas such as security, health, education, water, the enforcement of contracts, protection to property, protection to the environment and their ability to vote and get paid fair wages (Rotberg, 2014). Ejimabo (2013) sees Good governance in Nigeria as highly essential to the stability and growth of the nation and that of the economies of countries in the West African the Sub-region. Corporate governance, which will sometimes be used in lieu of workplace governance in this work, has been looked at in terms of corporate management, employee participation strategies, 
corruption in workplaces and so on. Rhodes (2007) argues that the analysis for the understanding of governance should include beliefs, practices, traditions, and dilemmas. Other scholars have also come up with various metrics to quantify governance. For example, Bhagat and Bolton (2019) suggested director stock ownership as a measure while Adnan, Hay and Staden (2018) believe that corporate governance can moderate detrimental effects of cultural influences on corporate social responsibility reporting and can help to mitigate the influence of national culture.

Through the ministries, departments, and agencies of the public sector of a nation, the government will tend to manage the economy and other factors instrumental to national development. Many issues may have been attributed to the dysfunctionality of many public corporate entities which may have also had an extrapolated effect on the Nigerian economy. Of all the myriads of attributable reasons for dysfunctionality, leadership is perhaps the most ubiquitous. Leadership is required in all aspects of national life to give direction and the needed impetus, to persons so assigned, to drive the various institutions that will culminate in the common good of the generality of the populace. Where leadership is dysfunctional, not much can be achieved. It has been posited that Africa will never be able to overcome its challenges, achieve its full potential, and protect itself from environmental and human exploitation unless and until there is effective leadership (Lituchy, Galperin \& Punnett, 2017). Similarly, other scholars have opined that if challenges such as the lack of proper accountability and management of public trust, corruption, political instability, maintenance of decaying amenities and infrastructures as well as inefficiency in governance are to be adequately tackled then there is a need to urgently address leadership issues in Nigeria (Ejimabo, 2013; Imhonopi \& Urim, 2013).

There is no gain saying that leadership is a crucial key driver in the push toward good governance. This is premised on the assumption that the powers inherent in a leadership position holder tend to exert overwhelming influence on the institutionalized processes and systems. The capacity of the holder of the leadership position to deliver on the mandates that will be in tandem with the desirability of the organization's long-term health will go a long way to determine if governance will be considered good or bad in the workplace.

In workplaces there is an observable apparent powerlessness in leadership that may be the bane of the workability of systems. This is demonstrated by the apparent lack of leadership capacity to act in a manner that will augur well with the corporate entity as well as the observable inability to have internal and external control of the use of the exalted leadership position. This work is a conceptual one which intends to explore Leadership-powerlessness visà-vis corporate governance to highlight the behavioral dispositions of persons in leadership positions in terms of their capacity to control the internal and external circumstantial triggers that accentuate the encumbrances and impediments of workplace governance outcomes.

\section{THEORETICAL BACKGROUND}

This work hinges on the Attribution Theory (Heider, 1958). The theory is based on the idea that people are naive psychologists and tend to interpret and explain their own behavior and the behavior of others by assigning attributes to behaviors. Attribution theory gives insight on how informed observers could explain causes and effects of behaviors. Dispositional (internal cause) and situational (external cause) attributions are two themes that emanated from this theory. The dispositional attribution tends to give explanation of behavior based on some internal features such as personality, personal values, principles, virtues, ideals or thought process instead of outside forces. On the other hand, the situational factors surrounding a person tend to guide a person's attitudes and behavior. Situational Attribution is the explanation that the cause of behavior is based on forces outside an individual's control. McLeod (2012) has noted that fundamental attribution error could occur when persons tend to explain the behavior of others as based on enduring internal attributions and make excuses for theirs based on external attributions. This work explores these internal and external dimensions to give meaning to the leadership-powerlessness construct.

The learned helplessness theory (Maier and Seligman, 1976) also guided this work. The theory presupposes that when an organism is forced to bear aversive, painful, or otherwise unpleasant stimuli, it gets to the point that it becomes unable or unwilling to avoid subsequent encounters with those stimuli, even if they are escapable. This tends to sometimes play out in corporate entities when there is a seemingly learned loss of control of situations due to external and, sometimes, internal pressures. In this situation one may look at leadership-powerlessness as a situation when persons feel helpless and unable to provide rational and logical solutions to challenges in spite of the exaltedness of the position they occupy. There is a display of complete inability to exert influence in a desired manner. Powerlessness may then imply that the significantly more powerful others are in possession of the reins of authority. In other situations, the internal nature of the value orientation operating within the individual holder of a leadership position renders him/her powerless.

\section{LEADERSHIP-POWERLESSNESS AND WORKPLACE GOVERNANCE}

The leadership of corporate entities has a lot to offer a nation, especially in terms of the wellbeing of the generality of the social environment. All the trending world issues ranging from global warming, growing inequality, to issues of the COVID 19 pandemic, as well as to other life changing issues that could affect organizational life, will require a leadership that will influence the fortunes of the organization in the direction that will yield positively desirable outcomes. The potency of the leadership when weighed on the mind scale of stakeholders and avid observers should be able to show the extent of influence and control exerted within the workspace. LeadershipPowerlessness, a paradox and an unorthodoxy which depicts leadership impotence, makes a leadership position holder 
unable to show moral courage and strength to challenge conventional draconian norms, stand by novel consensus decisions or even execute and implement corporate rules and procedures in a manner that will yield overall corporate benefits.

The thematic explorations as expressed in this work unbundles leadership- powerlessness into two. They are leadership-endopowerlessness and leadershipexopowerlessness. Leadership-endopowerlessness is the inability of an individual leadership position holder to control personal urges and shortcomings as well as show knowledge and capacity in the position being occupied. On the other hand, leadership-exopowerlessness is the inability of an individual occupying a leadership position to exert control over external social actors. The remaining part of this section discusses leadership-powerlessness in the aforementioned light.

\section{A. Leadership-endopowerlessness}

Leadership-endopowerlessness is a disposition that exists when a person occupying a leadership position demonstrates lack of self-control over internal urges and weaknesses such as greed, personal aggrandizement and other personal excesses that depict moral bankruptcy as well as the individual's inability to exhibit the requisite knowledge and expertise in handling the technicalities of the position so occupied. This level of powerlessness borders on the personal values and moral assets of a leadership position holder on one hand, and, on the other hand, the aptitude, skills, special abilities, and other competency characteristics that influence behavior. Put differently, Leadershipendopowerlessness is powerlessness based on the personality and abilities of the leadership position holder. One dimension of Leadership-endopowerlessness is based on the ability of the individual leader to have the conceptual and moral muscle to show expertise and courage in the performance of the assigned duties and in decision making. If the internal nature of value orientation of a person occupying a leadership position is patterned after those that tend towards moral bankruptcy the system will suffer monumental losses. Ebun (2016) believes that persons in the African continent tend to think that leadership positions are to get rich quickly and revenge the evils done to them or their tribes and has opined that the prevailing developmental level rating of Nigeria is based on the leadership orientation and goes further to blame bankruptcy of visionary and selfless leadership as the bane of the nation.

Leadership requires a lot of self-discipline and sacrifice (Jeb, 2012). The central thematic disposition of Leadershipendopowerlessness is that the power to alter the situation largely lies in the individual leadership position holder. This could be shown by the confidence level of the leadership position holder in the knowledge and ability to tackle the prevailing challenges and the ability to make people centered decisions not minding if his/her personal interest is subordinated. To reverse this level of leadershippowerlessness, there must be a personal conscious effort to combat the factors of disempowerment. For example, if a person occupying a leadership position chooses to have an alternative orientation or is sufficiently able to sensitize him/herself to tow a different line of thought, the pendulum could swing from powerless to powerful values such as honesty, transparency, credibility and modesty to mention a few. The greater the ability to curb such excesses the less powerless the leadership.

Ebun (2016) has surmised that leadership position holders have not been able to harness the human and economic resources of Nigeria due to certain anti-development attributes they possess which include corruption, intolerance, incompetence, rigidity, insensitivity, to mention a few. Also, there is the leadership inability to give organization members direction towards generally beneficial goals due to personal interests, charisma, and lack of power of persuasion. Galperin, Michaud, Senaji and Taleb (2019) observed that leader's knowledge capacity as well as the extent of the effectiveness of a leader's communication skills will help in ameliorating the current developmental situation.

Leadership-endopowerlessness seems to be a common phenomenon which is fast becoming a personal culture for persons with this level of powerlessness. This situation has had highly pernicious effects on the achievement of beneficial general interests. Adejimi (2005) has observed that it is common for policy makers as well as those involved in decision making in Nigeria, to engage in corrupt behaviors such as bribery, egoism, power, and trade liberalization. These leadership position holders tend to be distracted by their personal interests to the detriment of the interests of the generality of the members of the society. Lipset and Lenz (2000) have opined that cultures that stress economic successes as an important goal but, nevertheless, strongly restrict access to opportunities will have higher levels of corruption. Corruption is not only seen as a situation where persons unduly enrich themselves and personally gain from certain institutional processes but includes individual activities that negate the general good of the generality of the populace (Ugwuzor, 2021). This level of powerlessness becomes more glaring as there seems that there is an apparent lack of self-control. Asaju, Arome and Mukaila (2014) have advocated the need for moral education and constant value re-orientation as a panacea to what the authors termed leadership crisis. The many lofty solutions being put forward notwithstanding the country apparently remains in a deteriorating retrogressive mode.

\section{B. Leadership-Exopowerlessness}

Leadership-exopowerlessness is a state that subsists when a leadership position holder lacks control over external behavior influencing forces. These pressures exerted by these forces usually seem overwhelming to the person occupying the leadership position. These forces may stem from customs and traditions, societal values, emotional blackmail, impression management and have political, ethnic, religious, social and diverse other colorations that influence actions and inactions of the leadership position holder in corporate settings. Suffice it to say that not all persons will be influenced by the aforesaid forces in the same way. However, no matter how minute the influence may be, the leadership position holder feels some level of powerlessness and must seek logical institutional means of withstanding the situation. Ejimabo (2013) has noted the power of connections, underground networks, and political 
alliances in systems. This is perhaps the reason for leadership position holders seeking the seal of approval from sponsors and financiers as well as grapevine information before actions are taken. Lack of information to make correct decisions means higher powerlessness. Lack of information can lead to frustration if nothing is done about it. This can occur, if subordinates do not supply information or the leadership position holder is not with the informal social networks. Even when a leadership position holder feels the need to resign due to his/her inability to deliver on the assigned tasks and responsibilities, he/she will feel powerlessness to do so due to what society will say.

A person occupying a leadership position in an organization ought to have access to the resources, information and support necessary to carry out tasks. An effective leadership position holder should show capacity in the generation of innovative ideas in formal and informal activities. However, it is worthy to note the importance of the informal social system comprising networks of 'important personalities' that have a big say in the way decisions are made. Also, in situations where subordinate employee's bye-pass a supervisor to report a higher ranking personnel leaves the immediate supervisor powerless, if nothing is done. Such subordinate employees refuse to accept the legitimacy of the superior or deliberately do things tantamount to insubordination and resentfulness. When Supervisors have limited powers to punish and reward subordinates, endo-powerlessness occurs. If subordinates know that the superior officer does not have a say in their remuneration, the powerlessness of the superior in compounded. The outcomes of the organization may not reach its optimum if a leader with grand plans does not enjoy the support of other members of the organization. A manager's sense of powerlessness can be magnified when decisions that considerably affect the organization are made by the- powers- that- be outside the organization and handed down to the manager for implementation.

Powerlessness can also reflect in situations where there is responsibility without authority or accountability without power. In such cases, there is the demand to be accountable for the use of office when the power of the office holder to implement policies is limited or withheld by other formally and/ or informally institutionalized forces. There are also situations of responsibility without commensurate resources. Studies on leadership patterns in both Africa and the Africans in the diaspora, revealed that spirituality, tradition, and community centeredness are highly important determining factors for leadership behaviors (Michaud et al., 2020) This may imply that if the behaviors of those in leadership positions are able to produce outcomes that improve the endeavors they lead, then the attributing factors should be enhanced and replicated. However, Ugwuzor (2021) has posited that when ethnical norms of a society seem inimical to growth and development, such norms or acceptable practices are self- destructive and must be changed. The leadership behaviors as indicated by the very glaring need of development in Nigeria and other developing nations will need to be altered to reverse the prevailing trend.

\section{Workplace Governance}

One may not be able to completely capture the potency of leadership powerlessness unless x-rayed through the lens of workplace governance. Bhatt and Bhatt (2017) opine that firms with strong corporate governance outperform firms with weaker governance. Scherer and Voegtlin (2020) surmise that the challenges faced by humanity such as poverty, inequality, hunger, conflict, climate change, deforestation, and pandemics, among others, exist due to lack of innovative corporate governance. All of these, and more, indicators and measures notwithstanding, there seems to be a consensus that good governance is somewhat utopian, though largely achievable through concrete efforts and determination.

In organizations, leadership-powerlessness is a direct translation of the description of the level of effectiveness of the prevailing managerial governance behavior. Managerial governance behavior are behavioral outcomes of a manager in the execution of his/her duties in line with the tenets of workplace governance. Workplace governance is regarded in this work as the extent to which managerial behavior is in line with all the rationally accepted indices and metrics of efficiency and effectiveness in the handling of rules, procedures, Policies, and employee participation strategies all of which make for growth, sustainability, and survival of corporate entities. In other words, workplace governance is good when employees can have a voice in decision making and not a situation when majority will have their say but minority, their way; when decisions are not selfish nor based on self-interest; when there is satisfactory service delivery to customers and other stakeholders; highly reduced, intra organizational conflict; perceived equity, fairness and inclusiveness; employee engagement; rule of law as well as strict compliance with institutional regulations. Suffice it to say that leadership-powerlessness often creates situations of ineffectiveness, haphazardness, and gross disposition of inefficiency, to mention a few.

\section{Methodology}

This is a theoretical paper and utilized the exploratory research design to give more insight on the constructs and concerns raised by this Paper.

\section{WAYS FORWARD/CONCLUSION}

Recognizing the behaviors of the persons in leadership position is critical in the understanding of the enormity of the leadership-powerlessness anomaly. Leadershippowerlessness in this dimension can be characterized by the leadership positions holder's selfish behavior as well as other anti-people and eccentric leadership dispositions based on self-interests. The leader has to convincingly admit to $\mathrm{him} /$ herself this state of powerlessness and will desire to change from this state. If the perception of the situation is altered, then changes can occur. This alteration depends on the individual's ability to deliberately choose to distort the current mind state and re-discover him/herself. The inner strength to change may come from a genuine consciencestricken mental state. A gradual self-reorientation may begin to take place which show in a renewed novel behavioral pattern different for the previous state. In other cases, 
corporate and societal structures put in place check such excesses may be brought to bear. There are several policies and institutionalized structures to handle leadership excesses waiting for implementation. Examples of such include corporate disciplinary policies as well as other anticorruption and crime control mechanisms.

Exo-powerlessness could manifest in some activities of pressure groups within organizations and in situations such as when a person in leadership has to work with subordinates who cannot deliver on the mandates of their jobs. The power of the superior to produce results is sometimes limited to the output of the subordinates. Subordinates who are not empowered in terms of capacity and ability to meet work obligations, may sometimes worsen the state of powerlessness of the leadership position holder. This is particularly so in the public sector in Nigeria where the superior cannot hire and fire employees at will. Employee skilling, participation in decision making power sharing empowerment, delegating as well as other subordinate centred leadership and employee participation strategies could boost employee morale, reduce unnecessary critiquing, conflict, and combat exo-powerlessness.

The solution to the myriads of Challenges and the general malaise in harnessing developmental potentials in Africa in general and Nigeria in particular has been largely attributed to the empowered state of her leadership at the various levels of endeavors. In other words, leadershippowerlessness leads to bad governance. The greater the extent an individual leadership position holder is able to control endo and exo powerlessness the more likely it is to have good governance in corporate entities.

\section{REFERENCES}

Adnan, S. M., Hay, D.\& Van Staden, C.J. (2018). The influence of culture and corporate governance on corporate social responsibility disclosure: A cross country analysis. Journal of Cleaner Production, 198, 820-832.

Agere, S. (2000). Promoting good governance: Principle, practices and perspectives. London, United Kingdom: Commonwealth Secretariat.

Bhagat, S. \& Bolton, B. (2019). Corporate governance and firm performance: The sequel. Journal of Corporate Finance, 58, 142-168.

Bhatt, P.R. \& Bhatt, R.R. (2017). Corporate governance and firm performance in Malaysia, Corporate Governance 2 17(5), 896-912.

Ebun, O.D. (2016). Leadership and development in Nigeria: A critical analysis. International Journal of Politics and Good Governance, $7(7)$.

Ejimabo, N.O. (2013). Understanding the Impact of Leadership in Nigeria: Its Reality, Challenges, and Perspectives. SAGE Open Access Journal. 3 (2).

Galperin, B.L, Michaud, J., Senaji, T. A. \& Taleb, A. (2019). Perception of Leadership Effectiveness among the African Diaspora in Canada USA.

Heider, F. (1958). The Psychology of Interpersonal Relations. New York: Wiley.

IMF (2005). The IMF's approach to promoting good governance and combating corruption: A guide. International Monetary Fund. Retrieved August 12, 2021from https://www.imf.org/external/np/gov/guide/eng/index.htm.

Imhonopi, D. \& Urim, U. M (2013). Leadership crisis and corruption in the Nigerian public sector: An albatross of national development. The African Symposium, 13(1), 78-87.

Jeb, Blount (2012): People Follow You: The Real Secret to What Matters Most in Leadership. New Jersey: John Wiley \&Sons Incorporation.

Lituchy, T.R, Galperin, B. L \& Punnett, B.J. (2017). LEAD: Leadership Effectiveness in Africa and the African Diaspora. New York: Palgrave Macmillan.
McLeod, S. A. (2012). Attribution Theory. http://www.simplypsychology.org/attribution-theory.html. Retrieved on 10 October, 2021.

Michaud, J., Lvina, E., Galperin, B. L., Lituchy, T. R., Punnett, B. J., Taleb, Alleyne, A. (2020). Development and validation of the Leadership Effectiveness in Africa and the Diaspora (LEAD) scale. International Journal of Cross Cultural Management, 20(3), 361-384.

Rhodes, R. A. W. (2007). Understanding Governance: Ten Years On. Organization Studies, 28(8), 1243-1264.

Rotberg, R. (2014). Good Governance Means Performance and Results. Governance. 27 (3): 511-518.

Scherer, A.G. \& Voegtlin, C. (2020). Corporate governance for responsible innovation: Approaches to corporate governance and their implications for sustainable development. AMP, 34, 182-208.

Ugwuzor, M., (2021). Self-Destructive Work Behaviour Management for Socio- Economic Emancipation: A Classic Case of Saving One from Oneself. Journal of Economics and Behavioral Studies, 13(3(J), 3443.

World Bank (1992). Governance and development. Washington, D.C: The International Bank for Reconstruction and Development/ The World Bank. 